\title{
APPLICATION OF THE SPECTRAL METHOD TO STOCHASTIC FILTER ANALYSIS
}

\author{
O.I. Kharchenko \\ National Science Center “Kharkov Institute of Physics and Technology”, Kharkiv, Ukraine \\ E-mail: dthnbycrbq@gmail.com
}

The problem of standing out a signal from an additive mixture of a harmonic signal and white Gaussian noise is considered. The analysis is based on the phenomenon of stochastic resonance (SR), which consists in amplifying a periodic signal under the influence of noise of a certain power. SR is a universal physical phenomenon that is typical of some nonlinear systems, and is came out not only in technical, but also in biological and social systems. When calculating the spectral characteristics of the output signal, Volterra series were used. The problem is solved using the transfer functions of Volterra without the initial definition of kernels. Volterra transfer functions are obtained by the harmonic input signal method. The influence of the input signal parameters, in particular the amplitude and frequency of the harmonic signal and the noise power, on the spectral power density of the output signal is studied. Optimal parameters values are determined. Criteria are formulated for using a stochastic filter to standing out a harmonic signal on the background white Gaussian noise.

PACS: 05.45

\section{INTRODUCTION}

Nonlinear are systems in which processes do not satisfy to the superposition principle, unlike linear systems. All real physical systems are nonlinear, them it is possible to consider linear only approximately at small intensity of input signal. Mathematical models of nonlinear systems are the nonlinear equations. The analytical description of processes in nonlinear systems is complicated because there are no general methods of a solution of the nonlinear equations $[1,2]$.

The analysis on the basis of Volterra series is the most suitable method for modeling of schemes with weak nonlinearity [3].

Volterra series have been described as "power series with memory" which express the output of a nonlinear system in "power" of the input $x(t)$ [4]. The output signal of a nonlinear system is:

$$
y(t)=\sum_{n=1}^{\infty} \frac{1}{n !} \int_{-\infty}^{\infty} d u_{1} \ldots \int_{-\infty}^{\infty} d u_{n} g_{n}\left(u_{1}, \ldots, u_{n}\right) \prod_{r=1}^{n} x\left(t-u_{r}\right),
$$

where $y(t)$ is the output, $x(t)$ is the input and $g_{n}\left(u_{1}, \ldots, u_{n}\right)$ is the kernels, which describe the system. It will be noted that the first-order kernel $g_{1}\left(u_{1}\right)$ is simply the familiar pulse responce of a linear circuit. The higher order kernels can thus be viewed as higher order pulse responses which serve to characterize the various orders of nonlinearity.

The coefficient $1 / n$ ! was introduced by E. Bedrosian and O. Rice [4] to simplify many of equation. Any functional nonlinear system with no feedback consisting of inertial linear system and inertial nonlinearity can be described by Volterra series [5].

The analysis of a nonlinear component of a system is based on $n$-fold Fourier transform according to which $n$-fold transfer functions can be writing as [4]

$$
\begin{aligned}
& G_{n}\left(f_{1}, \ldots, f_{n}\right)=\int_{-\infty}^{\infty} d u_{1} \ldots \\
& \ldots \int_{-\infty}^{\infty} d u_{n} g_{n}\left(u_{1}, \ldots, u_{n}\right) \exp \left[-j\left(f_{1} u_{1}+\ldots f_{n} u_{n}\right)\right],
\end{aligned}
$$

where $G_{0}$ is identically equal zero in accordance with the system causality principle. Thus Volterra series starts with $n=1$ and $G_{1}\left(f_{1}\right)$ is transfer function of linear circuit. Spectrum conversion in linear systems realizes according to the superposition principle, excluding in a output signal harmonics which are absent in an input signal. In case of nonlinear systems the ratio between input and output frequencies is much more difficult $[1,2]$.

The complete formulas Volterra series are infinite series in which the laboriousness of computing the $n$-th term increases rapidly as $n$ increases. Fortunately, in the study of communication and radioengineering systems it is often possible to neglect terms in Volterra series of order higher then second or third [4].

In many cases transfer functions $G_{n}\left(f_{1}, \ldots, f_{n}\right)$ can be defined, without preliminary calculating a kernel $g_{n}\left(u_{1}, \ldots, u_{n}\right)$. Usually Volterra transfer functions are defined more simply, than multidimensional pulse responses.

Volterra transfer functions are determined by harmonic input method and received in [6].

\section{CHARACTERIZATION OF STOCHASTIC RESONANCE}

The problem of noise immunity is one of the central problems of radioengineering. Now there are designed many different methods of the radioengineering systems noise immunity increasing. The theory of potential noise immunity and optimum signal receiving is almost complete and became classical $[2,7,8]$, but all this methods are based, generally, on the principles of the linear signals analysis. However physicists came to paradoxical results in the eighties of the last century. Their researches in the theoretical and experimental physics showed that in some nonlinear devices additive noise can lead to increase the signal to noise ratio at the output [8]. This effect is called the stochastic resonance (SR).

SR is the universal physical phenomenon, which has been observed, quantified, and described in a plethora of physical and biological systems, including neurons and even social systems. 
Equation that illustrates a SR (other name is the nonlinear stochastic filter [9]) given by [10]

$$
\frac{d y}{d t}=a y-b y^{3}+x(t),
$$

where $a$ и $b$ are constants; $x(t)=s(t)+n(t)$ is input signal; $s(t)$ is periodic signal; $n(t)$ is Gaussian white noise $[10,11]$. The solution of the nonlinear equation of SR can be received on the basis of Volterra transfer functions without calculation of kernels $g_{n}\left(u_{1}, \ldots, u_{n}\right)$.

$$
a 1=\delta\left(f-f_{0}\right) A^{2} \frac{\left[2\left(a^{2}+\omega_{0}^{2}\right)\left\{2 a^{2}+3 b W_{I}\right\}+3 A^{2} b a\right]^{2}+16 a^{2} \omega_{0}^{2}\left(a^{2}+\omega_{0}^{2}\right)^{2}}{64 a^{2}\left(a^{2}+\omega_{0}^{2}\right)^{4}},
$$

where $W_{I}$ is two sided power spectrum density of the input white Gaussian noise; $a$ и $b$ are set in system parameters; $A$ is amplitude of the input sinusoidal signal; $\omega_{0}$ is frequency of the input sinusoidal signal.

The square of amplitude of a sinusoidal signal as a function of $W_{I}$ and $\omega_{0}$ when $A=1$ shown in Fig. 1.

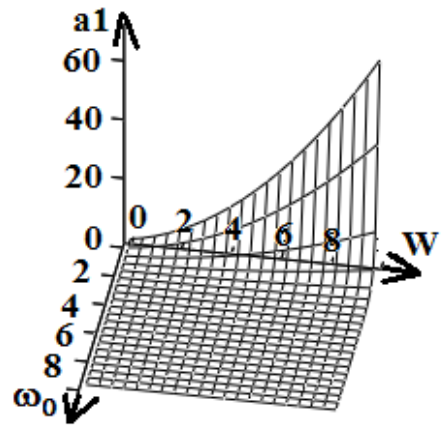

Fig. 1. The square of amplitude of a sinusoidal signal as a function of $W_{I}$ and $\omega_{0}$ for $A=1$

Results from Fig. 2 show that amplitude of a useful signal increases with increasing of input noise power, because of noise stands in the numerator of a formula (4) and helps to standing out a useful signal. It explains SR effect. Besides, amplitude of a useful signal sharply decreases with increasing of frequency of a harmonic signal that confirms one of SR properties, namely its low-frequency feature [10].

It is also obvious that amplitude of a useful output signal grows with growth of input signal amplitude that illustrates Fig. 2 (since input signal amplitude in (4) is in numerator).

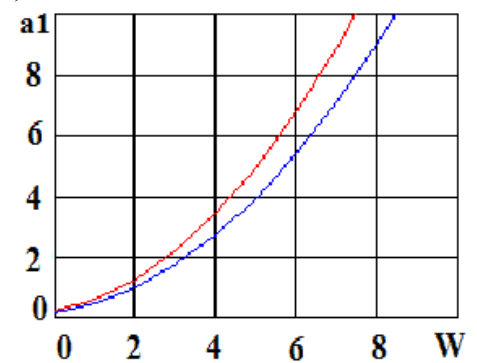

Fig. 2. The square of amplitude of a sinusoidal signal as a function of $W_{I}$ (red line for $A=1$, blue line for $A=0.9$ )

2. Let's consider a component of a output signal at a frequency of the third harmonic. It is defined as

\section{NONLINEAR STOCHASTIC FILTER DRIVING BY HARMONIC AND GAUSSIAN INPUT}

The main components of output power of the nonlinear stochastic filter, driving by harmonic and Gaussian input, are obtained in [12].

Let's consider the calculated components of an output signal in more detail:

1. The square of amplitude of a sinusoidal signal is given by.

$$
a 2=\delta\left(f-3 f_{0}\right) \frac{A^{6}}{64\left(1+9 \omega_{0}^{2}\right)\left(1+\omega_{0}^{2}\right)^{3}} .
$$

This harmonic demonstrates non-linear distortions of a signal. Amplitude of a harmonic signal must be less than unit for reduction of this component (since amplitude is included into numerator in the sixth degree). It also corresponds to one of SR properties, namely, the SR effect takes place at a weak input signal [10].

We can calculate this component as a function of $A$ for various values $\omega_{0}$ (Fig. 3).

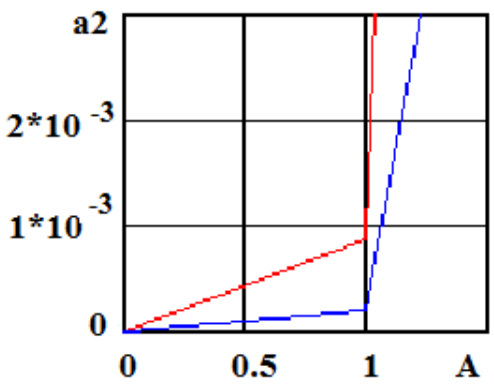

Fig. 3. The square of amplitude of a third harmonic as a function of $A$ (red line for $\omega_{0}=0.7$, blue line for $\omega_{0}=1$ )

Results of Fig. 3 show that component of an output signal at a frequency of the third harmonic it is much less than amplitude of a harmonic signal, especially at $A \leq 1$. It is because amplitude of a harmonic signal is in numerator in the sixth degree.

3. Let's consider the following component of a output power spectrum.

$$
a 3=W_{I} \frac{\left[\left(2 a^{2}+3 b W_{I}\right)\left(a^{2}+\omega_{0}^{2}\right)+3 A^{2} a b\right]^{2}+4 a^{2} \omega^{2}\left(a^{2}+\omega_{0}^{2}\right)^{2}}{4 a^{2}\left(a^{2}+\omega_{0}^{2}\right)^{2}\left(a^{2}+\omega^{2}\right)^{2}} .
$$

Fig. 3 shows this component.

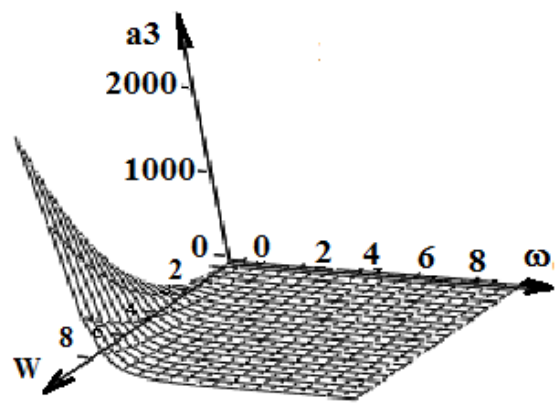

Fig. 4. The component a 3 as a function of $W_{I}$ and $\omega$ for $A=1$ 
Results from Fig. 4 show that the component $a 3$ increases with increasing of input noise power. Besides, this component drastically decreases with increasing of frequency.

Frequency of an input harmonic signal slightly influences this component that illustrates Fig. 5. If $\omega>4$, a3 goes to zero.

4. The following component of the output power spectrum is defined as:

$$
a 4=\frac{9 A^{4} b^{2} W_{I}}{16\left(a^{2}+\omega_{0}^{2}\right)^{2}\left(a^{2}+\left[\omega-2 \omega_{0}\right]^{2}\right)\left(a^{2}+\omega^{2}\right)} .
$$

It is obvious that this component increases with increasing of amplitude of an input harmonic signal and input noise power. Fig. 6 illustrates component $a 4$.

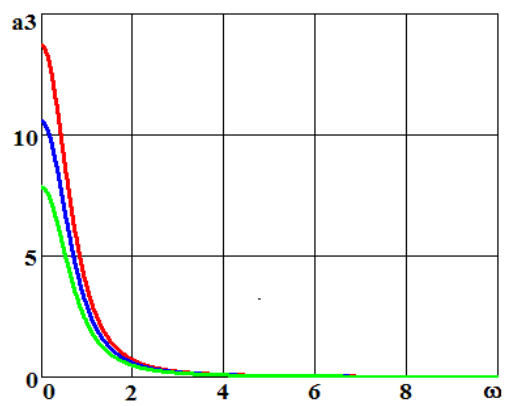

Fig. 5. The component a3 as a function of $\omega$ (red line for $\omega_{0}=0.5$, blue line for $\omega_{0}=1$, green line for

$$
\left.\omega_{0}=2 \text {; where } A=1 ; W_{I}\right)
$$

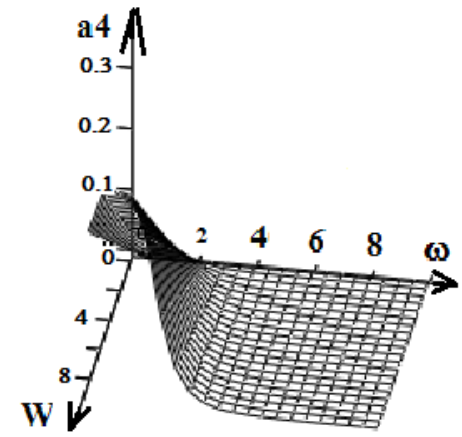

Fig. 6. The component a 4 as a function of $W_{I}$

$$
\text { and } \omega \text { for } A=1
$$

Results from Fig. 6 show that the component $a 4$ is significant only at low frequencies. Fig. 7 confirms this conclusion. The component $a 4$ becomes very small when $\omega>4$.

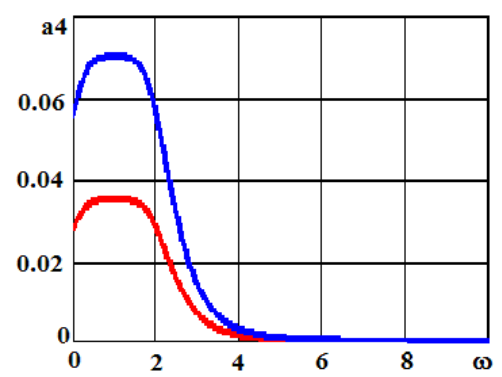

Fig. 7. The component $a 4$ as a function of $\omega$ (blue line for $W=2$, red line for $W=1$; where $A=1$;

$$
\omega_{0}=1 \text { ) }
$$

The maximum a4 does not depend on amplitude of the input sinusoidal signal and on input noise power spectrum and takes place at $\omega=\omega_{0}$. New extrema appear with increasing $\omega_{0}: \omega=\omega_{0}+\sqrt{\omega_{0}^{2}-a^{2}}$. Fig. 8 shows this results.

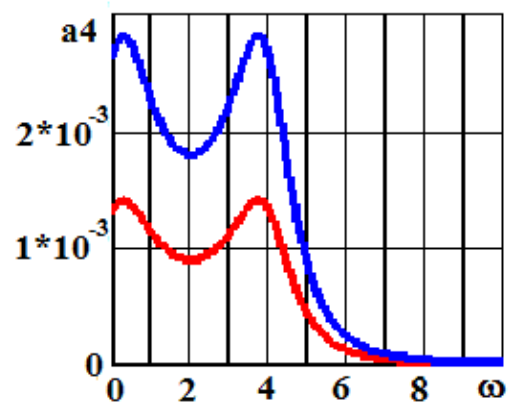

Fig. 8. The component a 4 as a function of $\omega$ (blue line for $W=2$, red line for $W=1$; where $A=1$;

$$
\omega_{0}=2 \text { ) }
$$

The component $a 4$ as a function of $\omega$ for various values $\omega_{0}$ shown on Fig. 9.

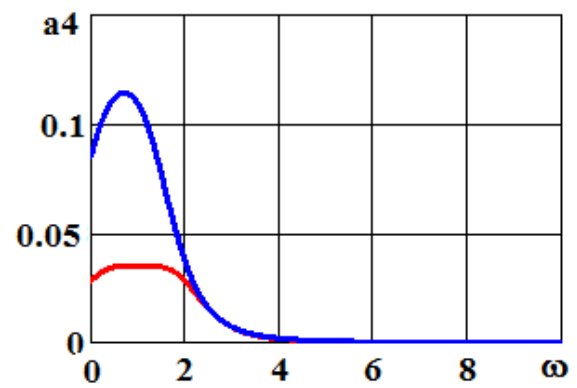

Fig. 9. The component a 4 as a function of $\omega$ (blue line for $\omega_{0}=1$, red line for $\omega_{0}=0.7$; where $W=1$;

$$
A=1 \text { ) }
$$

5. The following component of the output power spectrum is defined as:

$$
a 5=\frac{9 A^{4} b^{2} W_{I}}{16\left(a^{2}+\omega_{0}^{2}\right)^{2}\left(a^{2}+\left[\omega+2 \omega_{0}\right]^{2}\right)\left(a^{2}+\omega^{2}\right)} .
$$

As it is seen this formula is similar to a component $a 4$ expression. Fig. 10 shows that component $a 5$ drastically decreases with increasing of the input noise power and becomes very small when $\omega>4$. Component $a 5$ increases with increasing of the $A$ and $W_{I}$ since they are in the formula numerator. $A$ is in numerator in the fourth degree therefore for reduction of this component, it is necessary that $A$ was less than 1 .

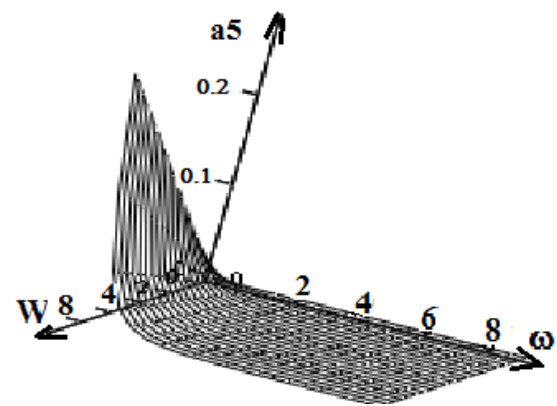

Fig. 10. The component a5 as a function of $W_{I}$ and $\omega$ for $A=1$ 
6. The following component of the output power spectrum is defined as:

$$
a 6=\frac{9 A^{2} b^{2} W_{I}}{2 a\left(a^{2}+\omega_{0}^{2}\right)\left(a^{2}+\omega^{2}\right)\left(4 a^{2}+\left(\omega-\omega_{0}\right)^{2}\right)} .
$$

As seen in Fig. 10, the component $a 6$ is significant only at low frequencies. Fig. 11 confirms this conclusion. The component $a 6$ becomes very small at $\omega>4$.

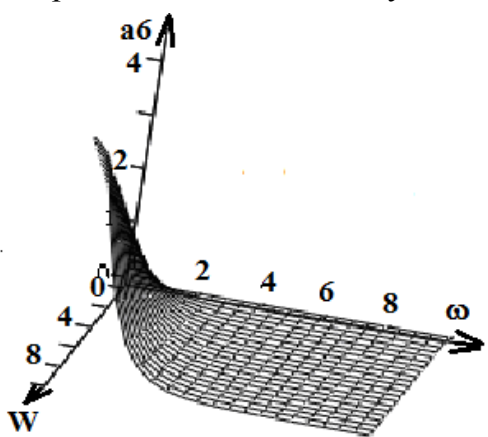

Fig. 11. The component a 6 as a function of $W_{I}$ and $\omega$ for $A=1$

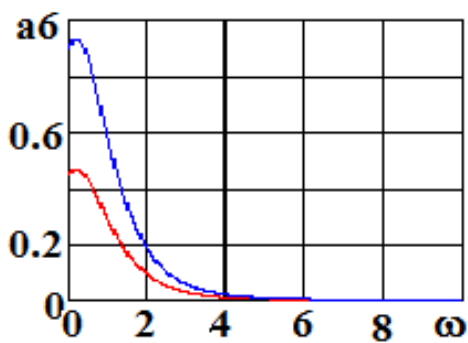

Fig. 12. The component a6 as a function of $\omega$ (blue line for $W=2$, red line for $W=1$; for $A=1$ )

Maximum $a 6$ is possible to define, having solved the equation

$$
2 \omega^{3}-3 \omega_{0} \omega^{2}+\left(5 a^{2}+\omega_{0}^{2}\right) \omega-a^{2} \omega_{0}=0
$$

using Cardano formula.

This component is symmetric relatively $\omega$ and $\omega_{0}$, therefore the component $a 6$ as a function of $\omega_{0}$ will be same as Fig. 11.

7. The following component of the output power spectrum is defined as:

$$
a 7=\frac{9 A^{2} b^{2} W_{I}}{2 a\left(a^{2}+\omega_{0}^{2}\right)\left(a^{2}+\omega^{2}\right)\left(4 a^{2}+\left(\omega+\omega_{0}\right)^{2}\right)} .
$$

Fig. 13 shows this component.

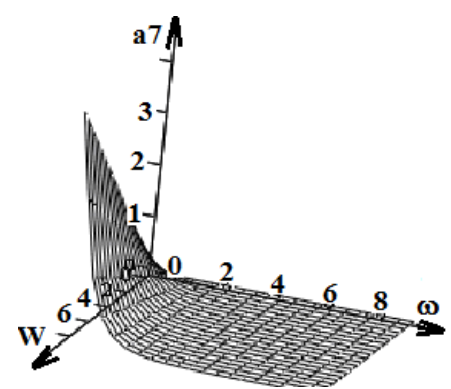

Fig. 13. The component a 7 as a function of $W_{I}$

$$
\text { and } \omega \text { for } A=1
$$

Component $a 7$ increases with increasing of the input noise power and decreases with increasing of the frequency, since this frequency is in a denominator with different degrees.

The component $a 7$ as a function of $\omega$ for various values $W_{I}$ shown on Fig. 14.

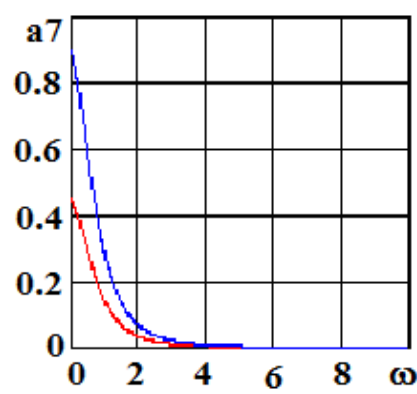

Fig. 14. The component a 7 as a function of $\omega$ (blue

line for $W=2$, red line for $W=1$; for $A=1$ )

It is well seen that the component $a 7$ is almost equal to zero when $\omega>4$.

This component is symmetric relatively $\omega$ and $\omega_{0}$, therefore the component $a 7$ as a function of $\omega_{0}$ will be same as Fig. 14.

8. The following component can be writing as:

$$
a 8=\frac{9 b^{2} W_{I}^{3}}{2 a^{2}\left(a^{2}+\omega^{2}\right)\left(\omega^{2}+9 a^{2}\right)} .
$$

This formula does not contain amplitude and the frequency of a input harmonic signal, therefore, this component does not depend on an input harmonic signal.

This component drastically increases with increasing of the input noise power and drastically decreases with increasing of the frequency. Fig. 15 shows this results.

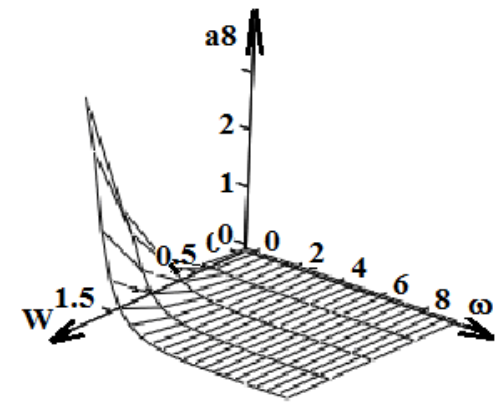

Fig. 15. The component a8 as a function of $W_{I}$ and $\omega$

Fig. 16 shows that the component $a 8$ is much more other components and makes a big contribution to an output signal. But at the same time the component $a 8$ becomes very small when $\omega>4$.

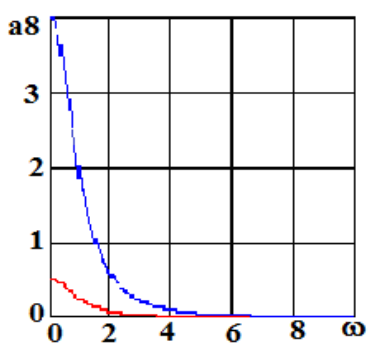

Fig. 16. The component $a 8$ as a function of $\omega$ (blue line for $W=2$, red line for $W=1$ ) 
These components having summarized, we will receive the power spectral density at the output of the stochastic filter (Fig. 17).

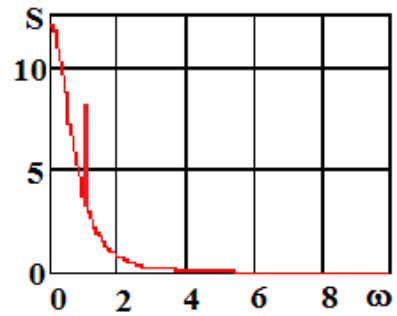

Fig. 17. The output power spectrum, as a function of $\omega$ where $A=1 ; W=1 ; \omega_{0}=1$

The dependence of power spectral density has the appearance characteristic of nonlinear systems [13]. It drastically decreases with increasing of the frequency, as seen in Fig. 17. The output power spectral density is almost equal to 0 when $\omega>4$. There are $\delta$-function at frequency of the input sinusoidal signal.

Unlike linear systems, the frequency composition of the power spectrum at the output of which remains unchanged, the power spectrum of the process at the nonlinear element output has a more complex structure [13]. At the output of the nonlinear system, new spectral components are formed due to the beating of the components of the input process. Moreover, their type and intensity are determined by the type of nonlinear transformation and the statistical characteristics of the process at the input.

\section{CONCLUSIONS}

The Volterra series is a powerful tool that can be used to describe a wide class of non-linear systems.

The received components of spectral power density allow to investigate influence of amplitude and frequency of an input sinusoidal signal, noise power, parameters of a system ( $a$ and $b$ ) on it.

Amplitude of a useful signal increases with increasing of input noise power, that explains SR effect, i.e. noise helps to standing out a useful signal. Besides, amplitude of a useful signal sharply decreases with increasing of frequency of a harmonic signal that confirms one of SR properties, namely its low-frequency feature.

Analysis of the frequency composition of the signal at the nonlinear stochastic filter output showed that the output component in the form of the delta function corresponds to the harmonic input signal at the input.

Component of a output signal at a frequency of the third harmonic it is much less than amplitude of a harmonic signal, especially at $A \leq 1$. That confirms one of SR properties, namely that input sinusoidal signal must be weak.
Obtained results is shown can be used as the basis for studying the dependence of the output signal spectrum on the parameters of a nonlinear filter.

\section{REFERENCES}

1. N.V. Zernov, V.G. Karpov. Teoriya radiotekhnicheskikh tsepey. M.-L.: "Energiya", 1965, 816 p. (in Russian).

2. Yu.I. Voloshchuk. Pidruchnik dla studentiv vich. navch. zakladiv. Kharkiv: TOV "Kompania CMIT", 2005, v. 3, 228 p. (in Russian).

3. N. Wiener. Nonlinear Problems in Random Theory. Cambridge, Mass. Technology Press; and New York Wiley, 1958.

4. E. Bedrosian, S. Rice. The Output Properties of Volterra Systems (Nonlinear Systems with Memory) Driven by Harmonic and Gaussian Inputs // IEEE. 1971, v. 59, № 12, p. 58-82.

5. K.A. Pupkov, V.I. Kapalin, A.S. Yushchenko. Funktsional'nyye ryady $v$ teorii nelineynykh sistem. M.: "Nauka" 1978, 448 p. (in Russian).

6. O.I. Kharchenko. Ispol'zovaniye apparata peredatochnykh funktsiy Vol'terra $\mathrm{v}$ reshenii zadachi stokhasticheskoy fil'tratsii s vkhodnym signalom $\mathrm{v}$ vide belogo Gaussova shuma // Visnyk NTUU KPI Seriia - Radiotekhnika Radioaparatobuduvannia. 2018, Iss. 73, p. 11-16 (in Russian).

7. Y.D. Shirman. Radioelektronnyye sistemy: osnovy postroyeniya i teoriya. Spravochnik. Izd. 2-ye pererab. i dop / Ya.D. Shirman, S.T. Bagdasaryan, D.I. Lekhovitskiy i dr. M.: «Radiotekhnika», 2007, 512 p. (in Russian).

8. Radiotekhnika: Entsiklopediya / Pod red. YU.L. Mazora, Ye.A. Machusskogo, V.I. Pravdy. M.: Izdatel'skiy dom "Dodeka-XXI", 2002, 944 p. (in Russian).

9. Yu.L. Klimontovich. Chto takoye stokhasticheskaya fil'tratsiya i stokhasticheskiy rezonans? // Uspekhi Fizicheskikh Nauk, Russian Academy of Sciences. 1999, v. 169, № 1, p. 39-47 (in Russian).

10. V.S. Anishchenko, A.B. Neiman, F. Moss, L. Schimansky-Geier. Stochastic resonance: noiseenhanced order // Uspekhi Fizicheskikh Nauk, Russian Academy of Sciences. 1999, 42(1)7-36, p. 7-34 (in Russian).

11. Xiaofei Zhang, Niaoqing $\mathrm{Hu}$, Zhe Cheng. Stochastic resonance in multi-scale bistable array // Physics Letter A 377. 2013, p. 981-984.

12. O.I. Kharchenko, V.M. Kartashov. Volterra transfer functions in analysis of the stochastic filter driven by harmonic plus gaussian noise input // Radiotechnika: All-Ukr. Sci. Interdep. Mag. 2019, № 169, p. 89-97.

13. B.R. Levin. Teoreticheskiye osnovy statisticheskoy radiotekhniki. M.: "Sovetskoye radio", 1969, 752 p. (in Russian). 


\section{ПРИМЕНЕНИЕ СПЕКТРАЛЬНОГО МЕТОДА К АНАЛИЗУ СТОХАСТИЧЕСКОГО ФИЛЬТРА}

\section{О.И. Харченко}

Рассмотрена задача выделения сигнала из аддитивной смеси гармонического сигнала и белого гауссова шума. В основу анализа положено явление стохастического резонанса (CР), которое заключается в усилении периодического сигнала под действием шума определенной мощности. СР является универсальным физическим явлением, которое типично для некоторых нелинейных систем, и проявляется не только в технических, но и в биологических и социальных системах. При расчете спектральных характеристик выходного сигнала использовались ряды Вольтерра. Задача решена с помощью передаточных функций Вольтерра без первоначального определения ядер. Передаточные функции Вольтерра получены методом гармонического входного сигнала. Исследовано влияние параметров входного сигнала, в частности амплитуды и частоты гармонического сигнала и мощности шума, на спектральную плотность мощности выходного сигнала. Определены значения оптимальных параметров. Сформулированы критерии применения стохастического фильтра для выделения гармонического сигнала на фоне белого гауссова шума.

\section{ЗАСТОСУВАННЯ СПЕКТРАЛЬНОГО МЕТОДУ ДЛЯ АНАЛІЗУ СТОХАСТИЧНОГО ФІЛЬТРА O.I. Харченко}

Розглянуто задачу виділення сигналу з адитивної суміші гармонійного сигналу і білого гаусова шуму. В основу аналізу покладено явище стохастичного резонансу (СР), яке полягає в посиленні періодичного сигналу під дією шуму певної потужності. СР є універсальним фізичним явищем, яке типове для деяких нелінійних систем, і проявляється не тільки в технічних, але і в біологічних, і соціальних системах. При розрахунку спектральних характеристик вихідного сигналу використовувалися ряди Вольтерра. Задача розв'язана допомогою передавальних функцій Вольтерра без початкового визначення ядер. Передавальні функції Вольтерра отримані методом гармонійного вхідного сигналу. Досліджено вплив параметрів вхідного сигналу, зокрема амплітуди і частоти гармонійного сигналу і потужності шуму, на спектральну щільність потужності вихідного сигналу. Визначено значення оптимальних параметрів. Сформульовано критерії застосування стохастичного фільтра для виділення гармонійного сигналу на тлі білого гаусова шуму. 